TITLE:

\title{
The effect of hip flexion angle on muscle elongation of the hip adductor muscles during stretching
}

$\operatorname{AUTHOR}(\mathrm{S}):$

Ogawa, Takuro; Saeki, Junya; Ichihashi, Noriaki

\section{CITATION:}

Ogawa, Takuro ...[et al]. The effect of hip flexion angle on muscle elongation of the hip adductor muscles during stretching. Journal of biomechanics 2020, 101: 109649.

ISSUE DATE:

2020-03-05

URL:

http://hdl.handle.net/2433/263896

\section{RIGHT:}

(c) 2020. This manuscript version is made available under the CC-BY-NC-ND 4.0 license: The full-text file will be made open to the public on 5 March 2021 in accordance with publisher's 'Terms and Conditions for Self-Archiving';.; This is not the published version. Please cite only the published version. この論文は出版社版でありません。引用の際には出版社 版をご確認ご利用ください。 
1 The Effect of Hip Flexion Angle on Muscle Elongation of the Hip Adductor Muscles

During Stretching

Takuro Ogawa $a^{a}$

6 Junya Saeki ${ }^{\mathbf{b}, \mathbf{c}}$,

$8 \quad$ Noriaki Ichihashi ${ }^{a}$

9

$10 \quad{ }^{a}$ Human Health Sciences, Graduate School of Medicine, Kyoto University, Japan

$11 \quad{ }^{b}$ Faculty of Sport Sciences, Waseda University, Japan

12 c Japan Society for the Promotion of Science, Japan

13 Corresponding Author:

14 Takuro Ogawa:

$15 \quad$ Email: ogawa.takuro.36m@st.kyoto-u.ac.jp

16 Human Health Sciences, Graduate School of Medicine, Kyoto University

1753 Shogoin-Kawahara-cho, Sakyo-ku, Kyoto, 606-8507, Japan 
18 Office phone: $+\mathbf{8 1 - 7 5 - 7 5 1 - 3 9 5 1}$

19 Office fax: $+\mathbf{8 1 - 7 5 - 7 5 1 - 3 9 5 1}$

20

21 Keywords; Shear wave elastography, Stretching, Adductor muscles

22

23 Word count: 2073 (Introduction through Discussion)

24

25

26

27

28

29

30

31

32

33

34 
Abstract

In order to perform effective static stretching of the hip adductor muscles, it is necessary

to clarify the position where the muscles are most stretched. However, the effective

flexion angle in stretching for each adductor muscle remains unclear. The goal of this study was to investigate the effect of hip flexion angle on muscle elongation of hip adductor muscles during stretching. Sixteen healthy men were recruited for this study. Shear elastic modulus, an index of muscle elongation, of the adductor longus (AL), and both the anterior and posterior adductor magnus (anterior $\mathrm{AM}$ ) were measured using ultrasonic shear wave elastography at rest (supine position) and at 5 stretching positions

44 (maximal hip abduction at $90^{\circ}, \mathbf{6 0}^{\circ}, \mathbf{3 0}^{\circ}, 0^{\circ}$, and $-15^{\circ}$ hip flexion). For the AL, the shear elastic modulus at rest was significantly lower than that in all stretching positions. However, there was no significant difference among stretching positions. For the anterior AM, there was no significant difference between stretching positions and at rest. For the posterior $\mathrm{AM}$, the shear elastic modulus in $90^{\circ}, 60^{\circ}$, and $30^{\circ}$ hip flexion were significantly higher than that at rest. The shear elastic modulus in $90^{\circ}$ hip flexion was significantly higher than that in $60^{\circ}$ and $30^{\circ}$ hip flexion. Our results suggest that the AL is elongated to the same extent by maximal hip abduction regardless of hip 
52 flexion angle, the anterior $\mathrm{AM}$ is not elongated regardless of the hip flexion angle; the

53 posterior $\mathrm{AM}$ is elongated at all angles except at $0^{\circ}$ and $-15^{\circ}$ hip flexion and is most

54 extended at $90^{\circ}$ hip flexion.

55

56

57

58

59

60 


\section{Introduction}

62 Adductor muscle strain is a common injury in athletes. A previous study investigating lower

63 limb muscle injuries in soccer players reported that the adductor muscle is the second most

64 common site of injury after hamstrings and is most likely to be reinjured (Ekstrand et al.,

65 2011). In addition, among the adductor muscles, the adductor longus (AL) is most commonly

66 injured (Kiel and Kaiser, 2018). Because a decrease in muscle flexibility is considered one

67 of the causes of adductor muscle strain injuries, improving the flexibility of muscles is important to prevent injuries (Ibrahim et al., 2007). Static stretching, which slowly stretches the muscle without bouncing or countermovement, is a method to increase muscle flexibility (Ichihashi et al., 2016). It is suggested that static stretching not only prevents muscle strain

71 injuries, but also reduces the time required for returning to competition after muscle strain

72 (Mason et al., 2012). Therefore, if the selective stretching method of each adductor muscle

73 (such as the AL, which is the most common site of muscle strain injury) is developed further,

74 it can be useful in the treatment of muscle strain and prevention of reinjury. In particular, men

75 had a higher rate of hip adductor strains than women(Eckard et al., 2017). Thus, it is

76 necessary to develop an effective stretching position suitable for men. 
78 It is reported that muscles whose forces have greater moment arms undergo greater passive

79 strain during joint motion (Magnusson et al., 2000). In the sagittal plane, AL and the anterior

80 adductor magnus (anterior AM) have hip flexion moment. On the other hand, the posterior

81 adductor magnus (posterior AM) has a hip extension moment (Dostal et al., 1987). Therefore,

82 the hip flexion angle may affect the amount of muscle elongation in the stretched muscle.

83 However, it remains unclear how the hip joint angle affects the stretching of the adductors. Ultrasonic shear wave elastography is used to evaluate muscle stiffness noninvasively in vivo. In this method, it is possible to quantitatively calculate the shear elastic modulus of tissue from the propagation shear wave velocity of the vibrated tissue when

87 radiation force is applied.(Brandenburg et al., 2014). Koo et al., (2013) reported a strong

88 linear relationship between the shear elastic modulus measured using ultrasonic shear wave

89 elastography and muscle stiffness. Therefore, ultrasonic shear wave elastography is an

90 eminent technique to estimate the muscle elongation in vivo (Umehara et al., 2015). The

91 purpose of this study was to investigate the influence of hip flexion angle during hip

92 abduction stretching of the adductor muscles using shear wave elastography. The hypotheses

93 are that the $\mathrm{AL}$ and anterior $\mathrm{AM}$, which generate flexion moments in the sagittal plane, are

94 most elongated in the hip extension position, and that the posterior AM, which generates an 
95 extension moment in the sagittal plane, is most elongated in hip flexion positions.

96

$97 \quad$ Materials and Methods

98

$\underline{\text { Participants }}$

99 The sample size required for multiple comparisons after a one-way repeated analysis of

100 variance (ANOVA) $[$ effect size $=0.8($ large $), \alpha$ error $=0.05$, Power $=0.80]$ was calculated in

101 advance via G*power software (version 3.1, Heinrich Hein University, Germany), and the

102 value was 15 . Therefore, 16 healthy men (age, $21.5 \pm 1.0$ years; height, $172.0 \pm 6.0 \mathrm{~cm}$;

103 weight, $72.2 \pm 7.6 \mathrm{~kg}$ ) were recruited for this study. All participants were fully informed of

104 the procedures and purpose of the study. Written informed consent was obtained from all

105 subjects. The ethics committee of Kyoto University Graduate School and the Faculty of

106 Medicine (R0233-3) approved this study.

\section{$\underline{\text { Experimental Protocol }}$}

109 The subjects were placed in a supine position. All measurements were taken on the right side.

110 The rest position (Rest) was determined as $0^{\circ}$ hip flexion, $0^{\circ}$ hip abduction position. The

111 stretching positions were maximum hip abduction at the following five hip flexion angles: 1) 
$112-15^{\circ}$ flexion (F-15); 2) $0^{\circ}$ flexion (F0); 3) $30^{\circ}$ flexion (F30); 4) $60^{\circ}$ flexion (F60); 5) $90^{\circ}$

113 flexion (F90); knee was maintained at $90^{\circ}$ flexion in all the five hip flexion angles (Fig 1).

114 The shear elastic modulus of the AL, anterior AM, and posterior AM were measured at Rest

115 and at the five stretching positions. The hip joints were passively moved to the maximal angle

116 at which the subjects did not feel discomfort or pain. The passive hip abduction ranges of

117 motion (ROM) at the five stretching positions were measured using a $1^{\circ}$-scale goniometer.

118 All measurements of ROM were performed twice, and the mean value was used for further

119 analysis. In addition, to eliminate the order effect, the stretching positions (i.e. flexion or

120 extension position of the hip) were determined in a random order, and the muscle

121 measurements were conducted randomly. Sustained stretching for more than 2 minutes

122 affects the elastic modulus of the muscles (Nakamura et al., 2014), so we took care to avoid

123 continuous stretching so that the measurement itself did not affect the elastic modulus.

125 Measurement of Shear Elastic Modulus

126 The shear elastic modulus of the AL, anterior AM, and posterior AM was measured using

127 ultrasound shear wave elastography (Aixplorer, Supersonic Imagine, France) with a linear

128 probe (SL10-2, Supersonic Imagine, France). The measurement site was defined as the 
129 proximal $30 \%$ of the upper leg length from the femoral greater trochanter to the knee joint

130 lateral space. The muscles were identified at this level with the use of a B-mode ultrasonic

131 image (Fig 2). In order to distinguish between the anterior AM and posterior AM, the anterior

132 AM was measured at the ventral end of the AM, and the posterior AM was measured at the

133 dorsal end of the AM (Fig 3). The shear elastic modulus was measured five times for each

134 muscle in each position, and the mean value was used for further analysis.

$136 \underline{\text { Statistical Analysis }}$

137 Statistical analysis was performed using statistical software (SPSS statistics version 22, IBM,

138 USA). To evaluate the intra-rater reliability of the shear elastic modulus measurements, the

139 intraclass correlation coefficient $(1,5)\left(\mathrm{ICC}_{1,5}\right)$ with a $95 \%$ confidence interval $(\mathrm{CI})$ was

140 calculated.

141 To investigate the difference of the shear elastic modulus across positions, a one-

142 way repeated measures analysis of variance (ANOVA) is used. A significant effect was

143 observed with the Holm multiple comparison test. In addition, a one-way repeated ANOVA

144 with a Holm multiple comparison test was also used to compare the ROM at different hip

145 flexion angles. The statistical significance was set at an alpha level of 0.05 , and all results 
146 were shown as mean $\pm \mathrm{SD}$.

$148 \underline{\text { Results }}$

149 The ICC $(1,5)$ was 0.99 (95\% CI: $0.979-0.996), 0.82$ (95\% CI: $0.619-0.935)$ and 0.85 (95\%

150 CI: $0.682-0.946$ ) for the shear elastic modulus of AL, anterior AM, and posterior AM at Rest,

151 respectively. For ROM, ICC $(1,2)$ values were 0.988 (95\% CI: 0.981-0.992).

153 shown in Fig 4. For AL, anterior AM, and posterior AM, one-way ANOVA indicated

154 significant main effects in positions. In the case of the AL, the post hoc test indicated that the

155 shear elastic modulus at each of the stretching positions was significantly higher than that at

156 Rest. However, there was no significant difference among the stretching positions. For the

157 anterior AM, there was no significant difference between stretching positions and at rest. For

158 the posterior $\mathrm{AM}$, the shear elastic modulus at $\mathrm{F} 90^{\circ}, \mathrm{F} 60^{\circ}$, and $\mathrm{F} 30^{\circ}$ hip flexion were

159 significantly higher than that at rest. The shear elastic modulus at F90 was significantly

160 higher than that at F60 and F30.

162 increased along with an increase in hip flexion angle. 


\section{$164 \quad \underline{\text { Discussion }}$}

165 This study investigated the influence of hip flexion angle on the stretching of each muscle

166 (AL, anterior AM, and posterior AM) during passive hip abduction. These muscles are

167 common sites of muscle strain. To the best of our knowledge, this is the first study that

168 investigated the effect of hip flexion angle on the muscle elongation of the individual

169 adductor muscles.

CI : $0.979-0.996), 0.822(95 \%$ CI : $0.619-0.935)$, and $0.852(95 \% \mathrm{CI}: 0.682-0.946)$ at AL,

172 anterior $\mathrm{AM}$, and posterior $\mathrm{AM}$, respectively. The $\operatorname{ICC}(1,2)$ values of the $\operatorname{ROM}$

173 measurements were $0.988(95 \% \mathrm{CI}: 0.981-0.992)$. Both values are greater than 0.81 and are

174 confirmed as "almost perfect" (Landis and Koch, 1977).

175 For the AL, the shear elastic modulus in all stretching positions was significantly

176 higher than at Rest, while there was no significant difference in shear elastic moduli among

177 the different stretching positions themselves. In other words, no difference was observed due

178 to the hip flexion angle. This result was different from the hypothesis that the AL is most

179 elongated in the hip extension position. We conclude that this is due to the influence of the 
180 hip abduction angle during stretching. Comparing the ROMs in each stretching position with

181 one another, we note that the hip abduction ROM increased with an increase of the hip flexion

182 angle. The AL has a flexion moment in most of the hip ROM (Dostal et al., 1987). However,

183 in the present study, the abduction angle was low at the hip extension position where the

184 muscle should be elongated, and the abduction angle was large at the flexion position, which

185 we concluded was the reason why no significant difference was observed. In summary,

186 regardless of the hip flexion angle, it was revealed that the AL is elongated to the same extent

187 by maximal abduction.

188 For the anterior AM, there was no significant difference between stretching

189 positions and at rest. This result was different from the hypothesis that the anterior AM is

190 most extended in hip extension. We consider another muscle to be a factor in limiting the

191 elongation of the anterior AM, and in constraining the ROM. A previous study reported that

192 the AL that is elongated in all stretching positions has a greater adduction and flexion moment

193 than the AM (Dostal et al., 1987). Therefore, the anterior AM was not elongated because the

194 AL was elongated before the anterior AM.

196 and F30 was significantly higher than that at Rest. This result is same as the hypothesis that 
197 the posterior AM is most elongated in the hip flexion position. We conclude that the reason

198 for the posterior AM not being elongated at F0 and F-15 is the effect of the change in moment

199 arm due to the flexion angle of the hip joint. Therefore, we conclude that the posterior AM is

200 not elongated at F0 and F-15 because the AL is elongated before the posterior AM, as in the

201 case of the anterior AM. Furthermore, the shear elastic modulus at F90 was significantly

202 higher than the shear elastic modulus at F60 and F30. It is considered that because the

203 posterior AM has a hip extension moment (Dostal et al., 1987), it is elongated more by

204 abduction from the hip flexion position.

205

There are some limitations in this study. Although this study evaluated the muscle

206 elongation during stretching using the shear elastic modulus, the actual effect of stretching

207 intervention was not examined, and it is unclear whether continuous stretching for a long

208 period of time will improve muscle flexibility. Future studies need to examine the effect and

209 duration of stretching by building on the present research work. In addition, the participants

210 in this study were limited to men. As men and women have different mechanical properties

211 in their muscles and function of their joints (Saeki et al., 2019), we should note that the results

212 presented in this study may not be applicable to female athletes.

213 In conclusion, this study examined the influence of the hip flexion angle on the 
214 stretching of the adductor muscles. It was revealed that the AL is elongated to the same extent

215 by maximal abduction regardless of the hip flexion angle, and the anterior AM is not

216 elongated regardless of the hip flexion angle, and the posterior AM was elongated at $90^{\circ}, 60^{\circ}$,

217 and $30^{\circ}$ hip flexion, and was most extended at $90^{\circ}$ hip flexion. To prevent injury, or to help

218 with rehabilitation after injury, we suggest that, to stretch the AL, the hip needs to be

219 maximally abducted regardless of the flexion angle, and to stretch the posterior AM, the hip

220 needs to be abducted at $90^{\circ}$ hip flexion.

222 Acknowledgements

223 We would like to thank Ms.Ibuki and Editage (www.editage.com) for English language 224 editing.

\section{Conflict of interest statement}

227 The authors declare that they have no conflict of interest.

\section{References}

230 Brandenburg, J.E., Eby, S.F., Song, P., Zhao, H., Brault, J.S., Chen, S., An, K.-N., 2014. 
Ultrasound elastography: the new frontier in direct measurement of muscle stiffness. Arch. Phys. Med. Rehabil. 95, 2207-19. https://doi.org/10.1016/j.apmr.2014.07.007

Dostal, W.F., Soderberg, G.L., Andrews, J.G., 1987. Actions of Hip Muscles. J. Pediatr. Orthop. 7, 245. https://doi.org/10.1097/01241398-198703000-00046

Eckard, T.G., Padua, D.A., Dompier, T.P., Dalton, S.L., Thorborg, K., Kerr, Z.Y., 2017. Epidemiology of Hip Flexor and Hip Adductor Strains in National Collegiate Athletic Association Athletes, 2009/2010-2014/2015. Am. J. Sports Med. 45, 2713-2722. https://doi.org/10.1177/0363546517716179

Ekstrand, J., Hägglund, M., Waldén, M., 2011. Epidemiology of muscle injuries in professional football (soccer). Am. J. Sports Med. 39, 1226-1232. https://doi.org/10.1177/0363546510395879

Ibrahim, A., Murrell, G.A.C., Knapman, P., 2007. Adductor strain and hip range of movement in male professional soccer players. J. Orthop. Surg. (Hong Kong) 15, 469. https://doi.org/10.1177/230949900701500111

Ichihashi, N., Umegaki, H., Ikezoe, T., Nakamura, M., Nishishita, S., Fujita, K., Umehara, J., Nakao, S., Ibuki, S., 2016. The effects of a 4-week static stretching programme on the individual muscles comprising the hamstrings. J. Sports Sci. 34, 2155-2159. 
https://doi.org/10.1080/02640414.2016.1172725

Kiel, J., Kaiser, K., 2018. Adductor Strain, StatPearls. StatPearls Publishing.

Koo, T.K., Guo, J.Y., Cohen, J.H., Parker, K.J., 2013. Relationship between shear elastic modulus and passive muscle force: An ex-vivo study. J. Biomech. 46, 2053-2059. https://doi.org/10.1016/j.jbiomech.2013.05.016

Landis, J.R., Koch, G.G., 1977. The Measurement of Observer Agreement for Categorical Data. Source: Biometrics 33, 159-174. stress and energy of the human hamstring muscles in vivo. Scand. J. Med. Sci. Sports

Mason, D.L., Dickens, V.A., Vail, A., 2012. Rehabilitation for hamstring injuries ( Review ). Cochrane Libr. https://doi.org/10.1002/14651858.CD004575.pub3.www.cochranelibrary.com

261 Nakamura, M., Ikezoe, T., Kobayashi, T., Umegaki, H., Takeno, Y., Nishishita, S., Ichihashi, N., 2014. Acute effects of static stretching on muscle hardness of the medial 
https://doi.org/10.1016/j.ultrasmedbio.2014.03.024

266 Saeki, J., Ikezoe, T., Yoshimi, S., Nakamura, M., Ichihashi, N., 2019. Menstrual cycle

267 variation and gender difference in muscle stiffness of triceps surae. Clin. Biomech.

268 (Bristol, Avon) 61, 222-226. https://doi.org/10.1016/j.clinbiomech.2018.12.013

269

Umehara, J., Ikezoe, T., Nishishita, S., Nakamura, M., Umegaki, H., Kobayashi, T., Fujita, K., Ichihashi, N., 2015. Effect of hip and knee position on tensor fasciae latae elongation during stretching: An ultrasonic shear wave elastography study. Clin. 


\section{Figure captions}

Fig 1. Stretching positions

$90^{\circ}$ hip flexion (a), $60^{\circ}$ hip flexion (b), $30^{\circ}$ hip flexion (c), $0^{\circ}$ hip flexion (d) and $-15^{\circ}$ hip flexion (e).

Fig 2. Shear elastic modulus analysis image

adductor longus (a), anterior adductor magnus (b), and posterior adductor magnus (c).

Fig 3. Shear elastic modulus measurement site of AM

AM: Adductor magnus, AL: Adductor longus, SM: Semimembranosus, ST:

Semitendinosus, G: Gracilis.

Fig 4. Shear elastic modulus of the (A) adductor longus (AL), (B) anterior adductor magnus (Anterior AM), and (C) posterior adductor magnus (Posterior AM) in each position.

Rest: $0^{\circ}$ hip flexion and $0^{\circ}$ hip abduction, F90: maximum hip abduction with $90^{\circ}$ hip flexion and $90^{\circ}$ knee flexion. F60: maximum hip abduction with $60^{\circ}$ hip flexion and $90^{\circ}$ 
knee flexion, F30: maximum hip abduction with $30^{\circ}$ hip flexion and $90^{\circ}$ knee flexion, F0: maximum hip abduction with $0^{\circ}$ hip flexion, $90^{\circ}$ knee flexion, F-15: maximum hip abduction with $-15^{\circ}$ hip flexion, $90^{\circ}$ knee flexion. *: Significant difference from Rest $(\mathrm{p}$ $<0.05)$. \#: Significant difference from F60 and F30 $(\mathrm{p}<0.05)$.

Fig 5. Hip abduction range of motion (ROM) in each position.

F90: maximum hip abduction with $90^{\circ}$ hip flexion and $90^{\circ}$ knee flexion. F60: maximum hip abduction with $60^{\circ}$ hip flexion and $90^{\circ}$ knee flexion, F30: maximum hip abduction with $30^{\circ}$ hip flexion and $90^{\circ}$ knee flexion, F0: maximum hip abduction with $0^{\circ}$ hip flexion, $90^{\circ}$ knee flexion, F-15: maximum hip abduction with $-15^{\circ}$ hip flexion, $90^{\circ}$ knee flexion. $\dagger$ : Significant differences between all positions. 
Fig 1
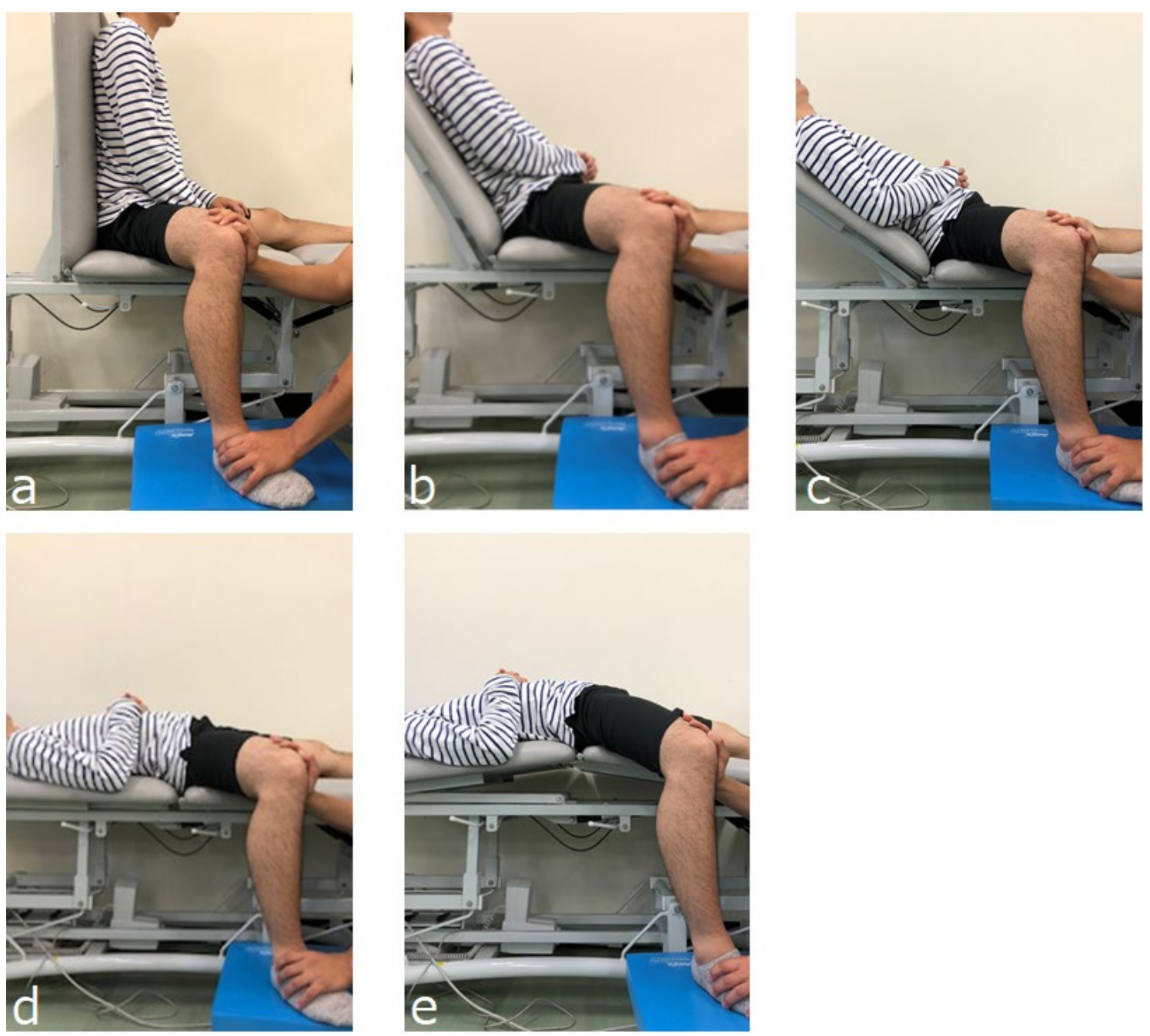
Fig 2

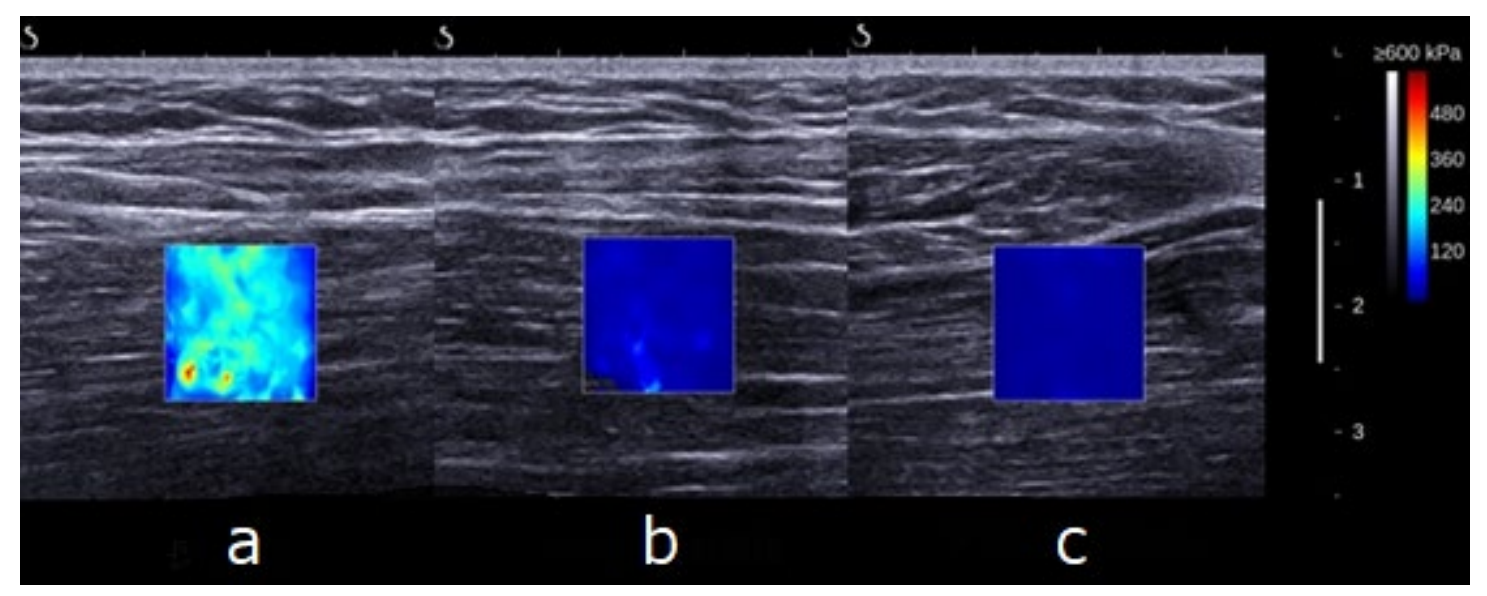


Fig 3

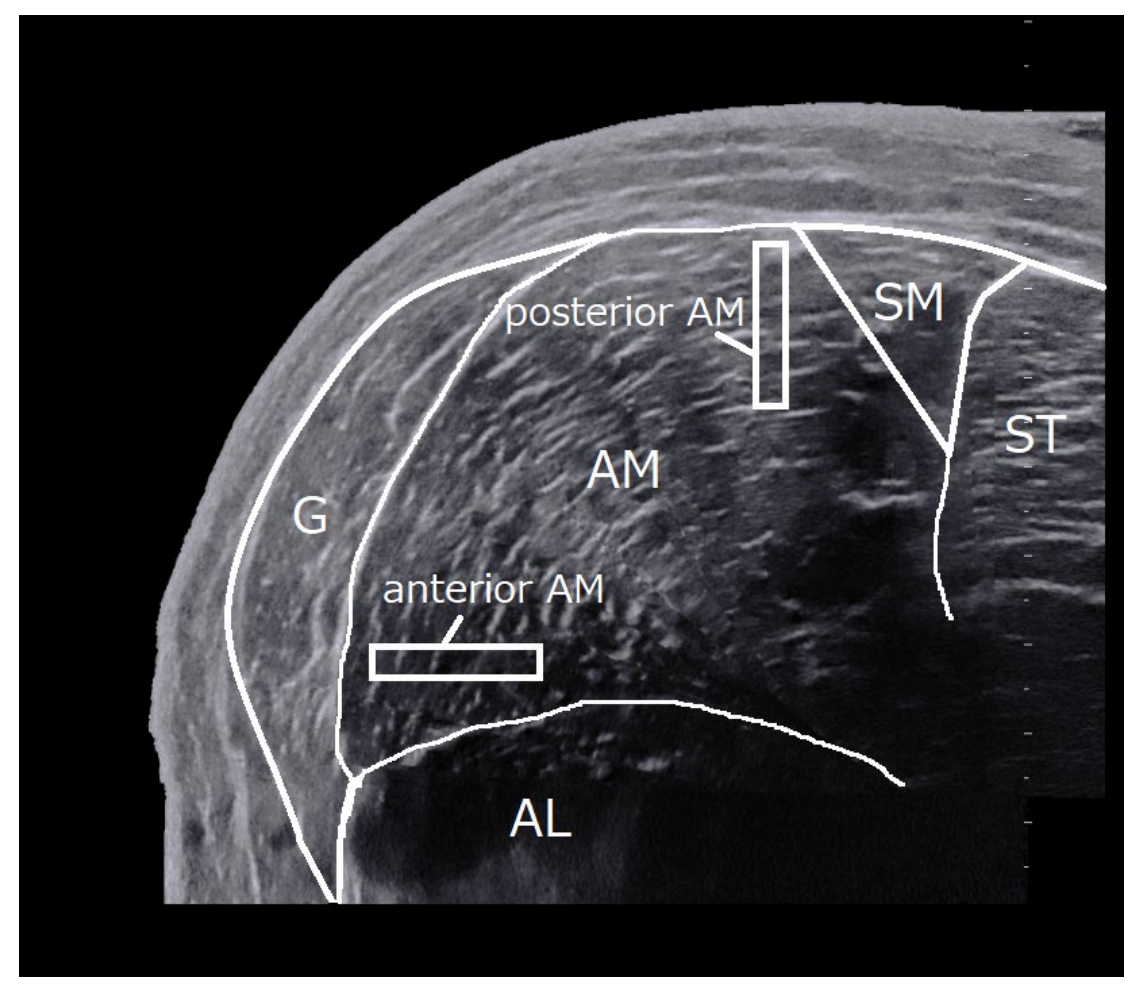


Fig 4

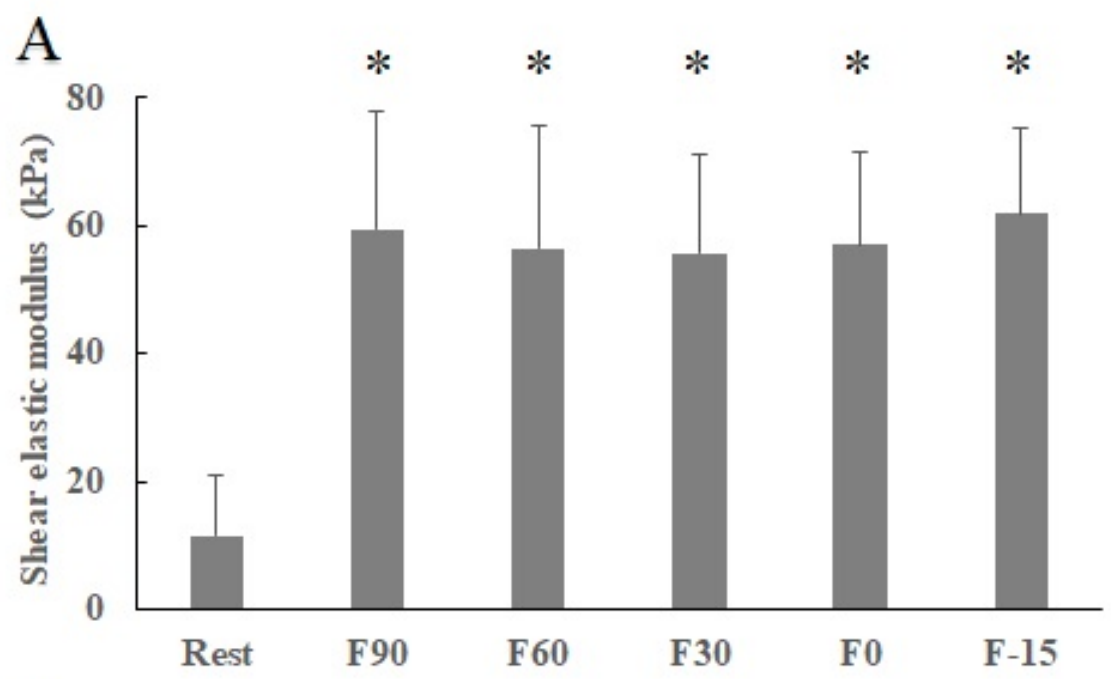

B
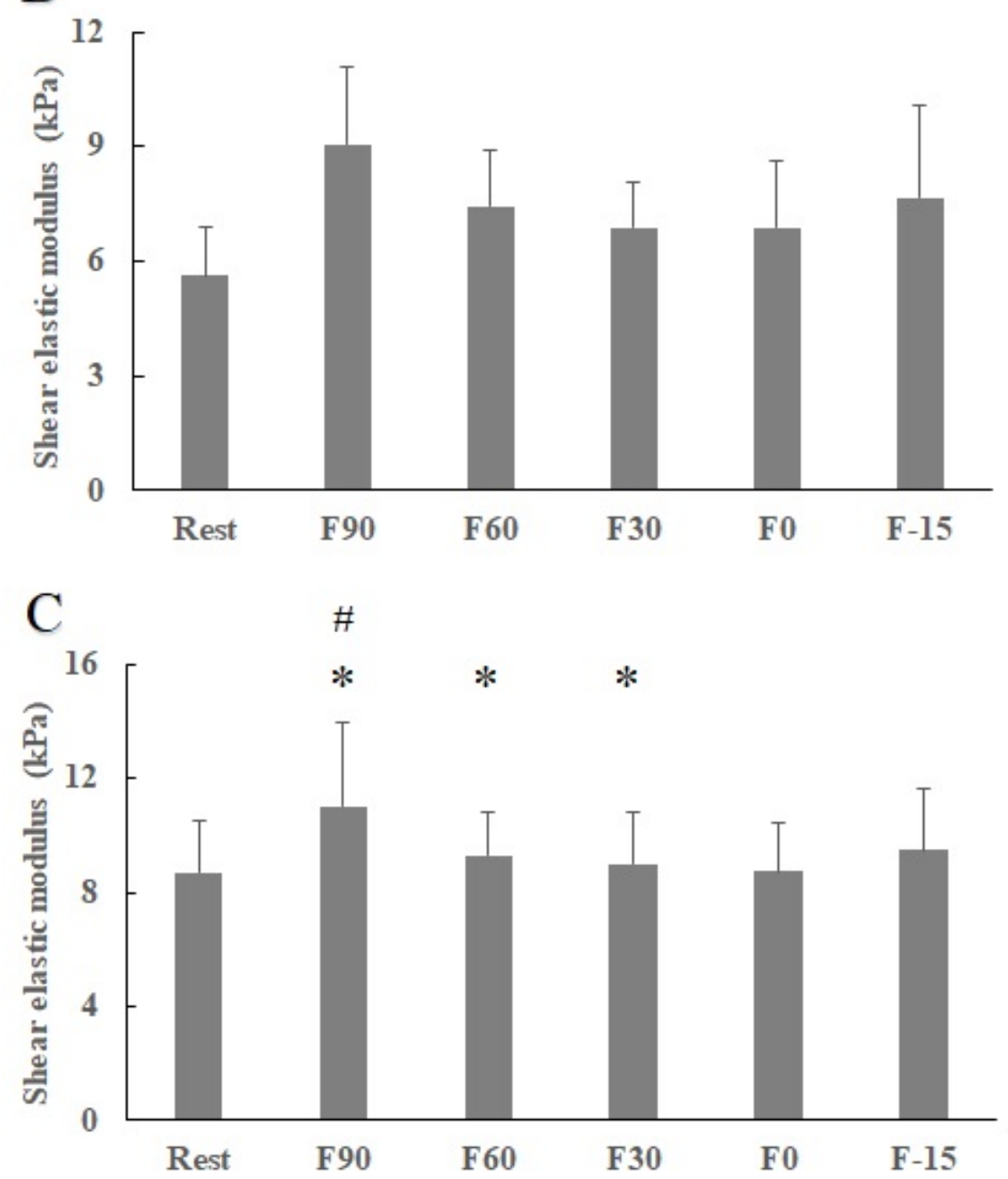
Fig 5

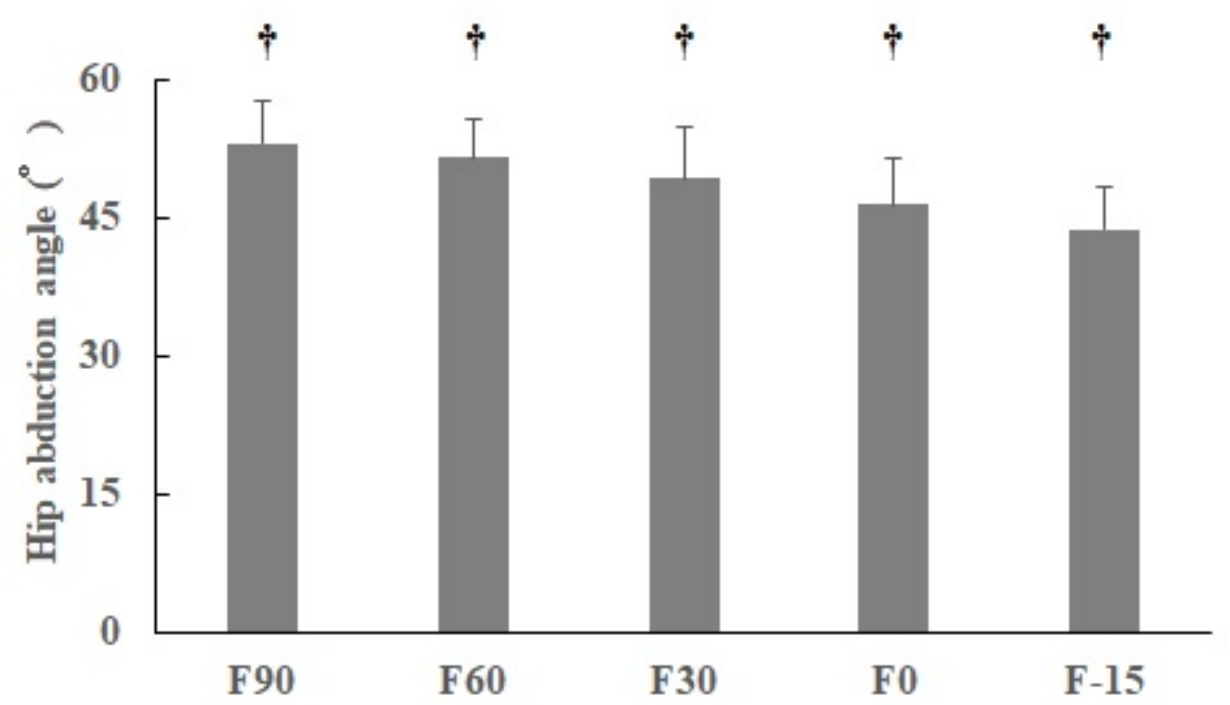

